\title{
Neuromuscular abnormality and autonomic dysfunction in patients with cerebrotendinous xanthomatosis
}

\author{
Shu-Fang Chen ${ }^{1,2}$, Nai-Wen Tsai ${ }^{1}$, Chung-Chih Chang ${ }^{1,2}$, Cheng-Hsien Lu', Chi-Ren Huang ${ }^{1}$, Yao-Chung Chuang ${ }^{1}$ \\ and Wen-Neng Chang ${ }^{1 *}$
}

\begin{abstract}
Background: Cerebrotendinous xanthomatosis (CTX) is a rare lipid-storage disease. Neuromuscular abnormality and autonomic system (ANS) dysfuction in CTX are rarely examined in large-scale studies in the literature. We studied the peripheral nervous system, myopathology, and autonomic system of four CTX patients and performed a literature review of the reported CTX patients with peripheral neuropathy.
\end{abstract}

Methods: Four biochemically and genetically confirmed CTX patients, belonging to two families, were included for study and all received nerve conduction study (NCS), muscle biopsy for histopathologic and ultrastructural study, skin biopsy for intraepidermal nerve fiber (INEF) density measurement, autonomic testings including sympathetic skin response, R-R interval variation and head-up tilt test using an automated tilt table to record the changes of blood pressure and heart rate in different postures. The Q-Sweat test was also applied for the detection of sweat amount and onset time of response. The clinical characteristics, study methods and results of 13 studies of peripheral neuropathy in CTX patients in the literature were also recorded for analysis.

Results: The results of NCS study showed axonal sensory-motor polyneuropathy in three CTX cases and mixed axonal and demyelinating sensor-motor polyneuropathy in one. The myopathological and histopathologic studies revealed mild denervation characteristics, but the ultrastructural study revealed changes of mitochondria and the membranous system, and increased amounts of glycogen, lipofuscin and lipid deposition. The ANS study revealed different degrees of abnormalities in the applied tests and the INEF density measurement showed small fiber neuropathy in three of the four CTX patients. The literature review of peripheral neuropathy in CTX revealed different types of peripheral neuropathy, of which axonal peripheral neuropathy was the most common.

Conclusions: Peripheral neuropathy, especially the subtype of axonal sensori-motor neuropathy, is common in patients with CTX. Evidence of lipid metabolic derangement in CTX can be reflected in ultrastructural studies of muscles. With an adequate multi-parametric evaluation, a high incidence of ANS abnormalities can be seen in this rare lipid-storage disease, and a high incidence of small fiber involvement is also reflected in the IENF density measurement of skin biopsies.

\section{Background}

Cerebrotendinous xanthomatosis (CTX), a rare autosomal recessive cholestanol lipidosis, is caused by a deficiency of the gene encoding the mitochondrial sterol 27-hydroxylase (CYP27A1) [1-4] and subsequently results in an abnormal deposition of cholestanol and

\footnotetext{
* Correspondence: cwenneng@ms19.hinet.net

'Department of Neurology, Kaohsiung Chang Gung Memorial Hospital and

Chang Gung University College of Medicine, Kaohsiung, Taiwan

Full list of author information is available at the end of the article
}

cholesterol in various organs. The major clinical presentations of CTX are juvenile cataracts, tendinous xanthomatosis and various neurological symptoms including dementia, pyramidal signs and cerebellar ataxia [1-4]. There have been case reports and small-scale studies on peripheral neuropathy in CTX using different measuring methods [5-17]. However, the state of the autonomic nervous system (ANS) $[14,16]$ and myopathologic features $[15,18]$ in CTX have rarely been reported, and different results have been noted among these limited

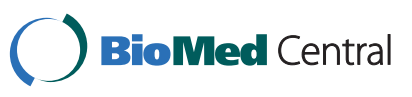

(C) 2011 Chen et al; licensee BioMed Central Ltd. This is an Open Access article distributed under the terms of the Creative Commons Attribution License (http://creativecommons.org/licenses/by/2.0), which permits unrestricted use, distribution, and reproduction in any medium, provided the original work is properly cited. 
studies. In this study, we reported the abnormalities of neuromuscular and ANS systems of four CTX patients and performed a literature review of the reported CTXrelated peripheral neuropathy.

\section{Methods}

\section{Patients}

The clinical data of the four included CTX cases are listed in Table 1. All four cases (Cases I-1, I-2, II-1 and II-2) had an elevation of serum cholestanol at presentation, with initial levels ranging from 24.7 to $46.8 \mathrm{ug} / \mathrm{ml}$ $($ mean $=34.3 \mathrm{ug} / \mathrm{ml}$, normal value $=3.37 \pm 1.55 \mathrm{ug} / \mathrm{ml})$. The diagnosis of CTX was made in 1991 in Family I, and 2004 in Family II. The clinical and neuroimaging features, and results of biochemical and genetic studies of these four CTX cases have been previously reported [19-21]. All four cases received chenodeoxycholic acid (CDCA) treatment $(750 \mathrm{mg} /$ day $)$ from the time of diagnosis. There were three CTX siblings in Family I, however one died before this study, and therefore only two were included in this study. This retrospective study was approved by the ethics committee of Chang Gung Memorial Hospital (IRB 99-3615B). Cases I-1 and I-2 (Family 1) and Cases II-1 and II-2 (Family II) have consented to publication of their clinical, laboratory and genetic data on March 30, 2006 and October 12, 2004, respectively.
Nerve conduction study and electromyography study

Nerve conduction studies (NCS) studies were performed using a VikingSelect system (Nicolet Biomedical Inc. Madison, USA). All testing was done in the same room and with the same temperature conditions, and the skin temperature was kept $\geqq 32^{\circ} \mathrm{C}$. The studied nerves included sural, tibial, peroneal, superficial radial, medial plantar, median and ulnar nerves. Amplitudes of the sensory action potential and compound muscle action potential as well as nerve conduction velocity, $\mathrm{F}$ wave response, distal latency and soleus- $\mathrm{H}$ reflex were recorded. In this study, the referential data for Chinese were cited from the report of Lin et al. [22]. In electromyographic (EMG) studies, the proximal and distal muscles of the upper and lower limbs were sampled.

\section{Muscle biopsies}

Muscle biopsies from the vastus lateralis of quadriceps were obtained with a BergstroÈm needle in all four CTX cases. Both histopathological and ultrastructural studies were processed according to standard proctocols [23-25]. The specimens processed for light microscopic investigations, were stained with haematoxylin/phloxine, ATPase, succinate dehydrogenase, cytochrome oxidase, Sudan black, periodic acid-Schiff and acid phosphatase. All muscle specimens were also prepared for ultrastructural examinations.

Table 1 Clinical data of the four cerebrotendinous xanthomatosis (CTX) patients

\begin{tabular}{|c|c|c|c|c|}
\hline \multirow{2}{*}{$\begin{array}{l}\text { Family } \\
\text { Case No }\end{array}$} & \multicolumn{2}{|l|}{1} & \multicolumn{2}{|l|}{ II } \\
\hline & 1 & 2 & 1 & 2 \\
\hline Gender & $\mathbf{F}$ & M & M & M \\
\hline Age (years) & 54 & 50 & 31 & 29 \\
\hline Age at CTX diagnosis (years) & 37 & 32 & 24 & 23 \\
\hline Disease duration at neuromuscular study (years) & 49 & 45 & 21 & 17 \\
\hline Body height $(\mathrm{cm})$ & 143 & 155 & 164 & 175 \\
\hline Body weight $(\mathrm{kg})$ & 45 & 50 & 74 & 114 \\
\hline Genetic mutation (CYP 27 gene) & \multicolumn{2}{|c|}{ Homozygous: 305delC (exon 2) } & \multicolumn{2}{|c|}{ Heterozygous: $1333 \mathrm{C}>\mathrm{T}($ exon 8$)$ and IVS 7+1G $>$ A (intron 7) } \\
\hline \multicolumn{5}{|l|}{ Clinical manifestation } \\
\hline Tendinous xanthomatosis & + & + & + & + \\
\hline Cataracts & + & + & + & + \\
\hline Osteoporosis with multiple fractures & + & + & - & - \\
\hline Mental retardation & + & + & + & + \\
\hline Cerebellar sign & + & + & + & + \\
\hline Pyramidal sign & + & + & + & + \\
\hline Parkinsonism & + & + & - & - \\
\hline Glove-stock paresthesia & - & - & - & - \\
\hline Hyporefelxia & - & - & - & - \\
\hline Distal foot muscle atrophy & - & - & - & - \\
\hline Posture related problems & - & - & - & - \\
\hline Sphincter problems & - & - & - & - \\
\hline Sweating problems & - & - & - & - \\
\hline
\end{tabular}

No = number + = present; - = absent; $F=$ female; $M=$ male 


\section{Skin biopsies and quantitation of skin innervation}

A punch skin biopsy of 3-mm in diameter was taken from the right distal leg $10 \mathrm{~cm}$ proximal to the lateral malleolus under local anesthesia with $2 \%$ lidocaine following the established protocol [26]. The sampled skin tissue was fixed in paraformaldehyde overnight. Sections $50 \mu \mathrm{m}$ perpendicular to the dermis were immunostained with antiserum to protein gene product 9.5 (PGP 9.5, 1: 1000; UltraClone, Isle of Wight, UK) and the reaction product was demonstrated using chromogen SG (Vector Laboratories).

Epidermal innervation was quantified according to established criteria in a coded fashion [27]. The observers were blinded to the clinical information. PGP 9.5 $(+)$ nerves in the epidermis of each skin section were counted at a magnification of $40 \times$ with a BX 40 microscope (Olympus, Tokyo, Japan). The length of the epidermis along the upper margin of the stratum corneum in each skin section was measured with ImageJ version 1.43 software (Image Processing and Analysis in Java, National Institutes of Health, Bethesda, MD: http:// rsbweb.nih.gov/ij/download.html). The intraepidermal nerve fiber (IENF) density was expressed as the number of fibers $/ \mathrm{mm}$ of epidermal length. In the distal leg, normative values (mean $\pm \mathrm{SD}$, 5th percentile) of IENF are $11.16 \pm 3.70$ (5.88) fibers $/ \mathrm{mm}$ for subjects aged $<60$ years and $7.64 \pm 3.08$ (2.50) fibers $/ \mathrm{mm}$ for subjects aged $\geqq 60$ years, and age- and gender-matched controls were retrieved from the previously described database [28].

\section{Autonomic function assessments}

Sympathetic skin response (SSR) and R-R interval variation (RRIV) were performed using a VikingSelect system (Nicolet Biomedical Inc. Madison, USA). RRIV is defined as heart rate (HR) variability in deep breathing test (patients are asked to breath at a rate of 6 breaths/ min ) as maximus HR -minimus HR/mean HR, and it is used to measure the cardiac parasympathetic activity [29]. Head-up tilt (HUT) tests for orthostatic blood pressure (BP) and heart rate (HR) changes were performed on an automated tilt table. Patients were first placed in a supine position and then tilted to 70 degrees. Data recorded using a continuous monitor (Finapres BP monitor 2300, Finameter Pro, Ohmeda; Englewood, OH, USA) included systolic, diastolic, and mean BP continuously in serial recordings at $0,1,2,3$, and 5 minutes after tilting up, and at the third minute after lying back. In this study, "orthostatic hypotension" was defined as a reduction in a systolic BP of $\geqq 20 \mathrm{mmHg}$ or a diastolic BP of $\geqq 10 \mathrm{mmHg}$ within three minutes of upright tilt to an angle of $\geqq 60^{\circ}$ or standing. We used a "30:15 ratio" which may denote the cardiac parasympathetic activity [30], to assess this physiological response by measuring the ratio of the RR interval at beat 30 while standing to the RR interval at beat 15 . The slope of the regression line between the R-R interval and systolic $\mathrm{BP}$ values was computed for each sequence, and taken as a measurement of baroreflex sensitivity (BRS, $\mathrm{ms} / \mathrm{mmHg}$ ) which may measure both sympathetic and parasympathetic activities [31] in this HUT study [32].

\section{Q-Sweat recordings}

The Q-Sweat recording was performed at the same room temperature $\left(21-23^{\circ} \mathrm{C}\right)$, room humidity $(56-58 \%)$ and skin temperatures over the tested sites $\left(>34^{\circ} \mathrm{C}\right)$. All four CTX cases underwent left limb Q-Sweat recordings using the standard regional sites (forearm, proximal leg, distal leg, and foot) with a Q-Sweat device (WR Medical Electronics Co, Stillwater, Minnesota, USA) by the evoke of acetylcholine solution $(10 \% \mathrm{w} / \mathrm{v})$. Sweat amount and onset time of response were displayed using TestWorks software (WR Medical Electronics Co., Stillwater, Minnesota) [33]. In addition, 90 sex- and age-matched healthy subjects from the normative database acted as control for this test. The human ethics committee of Chang Gung Memorial Hospital approved the study (IRB98-0805B).

\section{Reported CTX patients with peripheral neuropathy in the literature}

For a better delineation of peripheral neuropathy features in CTX patients, the clinical data and described types of peripheral neuropathy reported in the literature [5-17] were included for analysis.

\section{Results \\ NCS and EMG}

The results of the NCS study of the four CTX cases showed a mild axonal sensory-motor polyneuropathy characterized by a decreased amplitude in sensory and motor nerves, and an absent response in the sural nerves in Cases I-1, I-2 and II-2, and mixed axonal and demyelinating sensory-motor polyneuropathy characterized by slowed nerve conduction velocity, prolonged $\mathrm{F}$ response and absent response in sural nerves in Case II-1 (Table 2). In EMG studies, only denervation changes characterized by decreased recruitment patterns and increased polyphasic waves in the distal muscles were detected.

\section{Muscle biopsies}

In light microscopic examination, no histopathologic features suggesting myopathic change were noted, but small grouping denoting slight neurogenic changes was observed. The findings of the ultrastructural study are listed in Table 3 and demonstrated in Figure 1.

\section{Quantitation of skin innervations}

The IENF densities were as follows: 3.19 fibers $/ \mathrm{mm}$ in Case I-1, 6.14 fibers $/ \mathrm{mm}$ in Case I-2, 5.45 fibers $/ \mathrm{mm}$ in 
Table 2 Nerve conduction study findings of the four cerebrotendinous xanthomatosis patients

\begin{tabular}{|c|c|c|c|c|c|c|c|c|c|c|}
\hline \multirow[t]{2}{*}{ Case } & & \multicolumn{2}{|c|}{ Median } & \multicolumn{2}{|c|}{ Ulnar } & \multirow{2}{*}{$\begin{array}{l}\text { Superficial } \\
\text { radial }\end{array}$} & \multirow[t]{2}{*}{ Peroneal } & \multirow[t]{2}{*}{ Tibial } & \multirow[t]{2}{*}{ Sural } & \multirow{2}{*}{$\begin{array}{l}\text { H-reflex (N } \\
<27.6)\end{array}$} \\
\hline & & Motor & Sensory & Motor & Sensory & & & & & \\
\hline \multirow[t]{8}{*}{$1-1$} & R DL (ms) & $4.4(N<3.6)$ & 2.8 & $2.9(\mathrm{~N}<2.8)$ & 2.2 & 1.9 & $4.0(N<4.2)$ & $2.7(\mathrm{~N}<4.9)$ & Absent & 31.0 \\
\hline & L DL (ms) & 4.4 & 3.0 & 2.5 & 2.9 & 1.7 & 4.0 & 3.7 & Absent & 30.4 \\
\hline & $\mathrm{R} C V(\mathrm{~m} / \mathrm{s})$ & $50(\mathrm{~N}>57.8)$ & $50(\mathrm{~N}>51.7)$ & $50(N>61.4)$ & $56(N>56.3)$ & $63(N>50)$ & $39(N>48.6)$ & $45(\mathrm{~N}>50.5)$ & $\begin{array}{l}\text { Absent } \\
(\mathrm{N}>47.4)\end{array}$ & \\
\hline & $\mathrm{L} C V(\mathrm{~m} / \mathrm{s})$ & 49 & 47 & 54 & 49 & 71 & 42 & 40 & Absent & \\
\hline & R Amp & $7.6(\mathrm{~N}>11.9)$ & $47(\mathrm{~N}>33)$ & $11(\mathrm{~N}>11.7)$ & $32(N>26.1)$ & $23(N>15)$ & $4.1(\mathrm{~N}>6.0)$ & $5.5(\mathrm{~N}>13.1)$ & $\begin{array}{l}\text { Absent } \\
(N>12.5)\end{array}$ & \\
\hline & L Amp & 7.1 & 21 & 8.1 & 38 & 33 & 4.5 & 9.6 & Absent & \\
\hline & R F waves & $\begin{array}{c}26.8-0.7 \\
(\mathrm{~N}<25.4)\end{array}$ & & $\begin{array}{c}27.0-0.8 \\
(\mathrm{~N}<25.0)\end{array}$ & & & $\begin{array}{l}49.8-0.4 \\
(\mathrm{~N}<44.7)\end{array}$ & $\begin{array}{l}50.2-0.8(\mathrm{~N}< \\
45.0)\end{array}$ & & \\
\hline & LF waves & 27.9-0.8 & & $26.4-1.0$ & & & $47.4-0.4$ & $50.4-0.8$ & & \\
\hline \multirow[t]{8}{*}{$1-2$} & $\mathrm{R} \mathrm{DL}$ (ms) & 4.4 & 2.7 & 3.2 & 2.6 & 2.1 & 4.2 & 5.0 & Absent & 32.4 \\
\hline & L DL (ms) & 4.0 & 2.8 & 3.0 & 2.2 & 1.8 & 3.9 & 3.3 & Absent & 32.6 \\
\hline & $\mathrm{R} C V(\mathrm{~m} / \mathrm{s})$ & 49 & 53 & 54 & 46 & 57 & 39 & 41 & Absent & \\
\hline & $\mathrm{L} C V(\mathrm{~m} / \mathrm{s})$ & 51 & 50 & 51 & 54 & 67 & 41 & 40 & Absent & \\
\hline & R Amp & 8.6 & 23 & 7.3 & 26 & 34 & 2.9 & 10.5 & Absent & \\
\hline & L Amp & 9.2 & 31 & 8.8 & 13 & 60 & 3.8 & 6.7 & Absent & \\
\hline & R F waves & $30.0-0.5$ & & $28.8-1.0$ & & & $50.5-1.0$ & $51.8-1.0$ & & \\
\hline & LF waves & $28.3-1.0$ & & $28.4-1.0$ & & & $50.1-0.6$ & $53.9-1.0$ & & \\
\hline \multirow[t]{8}{*}{$\|-1$} & R DL (ms) & 4.3 & 2.8 & 3.0 & 2.4 & 2.1 & Absent & 4.5 & Absent & 38.4 \\
\hline & L DL (ms) & 4.1 & 3.0 & 2.8 & 2.5 & 2.0 & 4.9 & 5.1 & Absent & 37.5 \\
\hline & $\mathrm{R} C V(\mathrm{~m} / \mathrm{s})$ & 44 & 50 & 42 & 50 & 56 & Absent & 32 & Absent & \\
\hline & $\mathrm{L} C V(\mathrm{~m} / \mathrm{s})$ & 46 & 47 & 43 & 48 & 60 & 30 & 34 & Absent & \\
\hline & R Amp & 10.3 & 42 & 11.5 & 20 & 25 & Absent & 4.0 & Absent & \\
\hline & L Amp & 11.7 & 47 & 9.9 & 29 & 32 & 2.4 & 2.6 & Absent & \\
\hline & R F waves & $32.6-1.0$ & & $32.1-1.0$ & & & Absent & $70.6-0.6$ & & \\
\hline & LF waves & $30.4-0.9$ & & $30.4-1.0$ & & & $79.2-0.2$ & $75.7-0.9$ & & \\
\hline \multirow[t]{8}{*}{$\|-2$} & R DL (ms) & 4.0 & 2.5 & 2.8 & 2.0 & 1.7 & 4.4 & 3.4 & Absent & 31.9 \\
\hline & L DL (ms) & 4.2 & 2.7 & 3.0 & 2.3 & 1.7 & 3.8 & 3.8 & Absent & 31.6 \\
\hline & $\mathrm{R} C V(\mathrm{~m} / \mathrm{s})$ & 52 & 56 & 58 & 60 & 71 & 39 & 41 & Absent & \\
\hline & $\mathrm{L} C V(\mathrm{~m} / \mathrm{s})$ & 52 & 52 & 50 & 53 & 71 & 43 & 39 & Absent & \\
\hline & R Amp & 8.5 & 29 & 6.6 & 38 & 16 & 3.2 & 4.7 & Absent & \\
\hline & L Amp & 7.4 & 50 & 6.7 & 40 & 29 & 4.7 & 2.0 & Absent & \\
\hline & R F waves & $29.8-1.0$ & & $30.4-0.8$ & & & $54.2-0.3$ & $53.3-1.0$ & & \\
\hline & L F waves & 29.6-1.0 & & $31.6-0.9$ & & & $50.9-0.8$ & $56.5-0.9$ & & \\
\hline
\end{tabular}

$\mathrm{N}=$ normal; $\mathrm{DL}=$ distal latency; $\mathrm{CV}=$ conduction velocity; $\mathrm{Amp}=$ amplitude ( $\mathrm{mV}$ in motor nerves and $\mu \mathrm{V}$ in sensory nerves); $\mathrm{F}$ waves = minimal latencypersistent rate; $\mathrm{H}$-reflex = soleus $\mathrm{H}$-reflex in minimal latency; $\mathrm{AT}=$ anterior tibialis; $\mathrm{FDI}=1$ st dorsal interosseous muscle; $\mathrm{R}=$ right; $\mathrm{L}=$ left

Case II- 1 and 5.13 fibers $/ \mathrm{mm}$ in Case II-2. This result showed a decrease of IENF in Cases I-1, II-1 and II-2.

\section{Results of autonomic testings (Table 4)}

In RRIV measurement, decreased value was found in Case I-1. In SSR measurement, no abnormal responses were detected on either the soles or palms of these four cases. The results of the HUT test showed: 1) no abnormal orthostatic HR or BP changes in all four cases; 2) abnormally decreased values in Cases I- 1 and I- 2 in the measurement of the "30:15 ratio"; and 3) negative and decreased values in Cases I-1 and I-2 in BRS measurement.

In the Q-Sweat test, compared with the data of normal control (Table 4), sweat output showed a reduction of sweat volume only in the forearm and foot of Case II-1. With a relative comparison, the sweat volumes were as follows: foot sweat volume $<1 / 3$ of the forearm value in Case I-1; foot and proximal leg < $1 / 3$ of the forearm value in Case I-2; and forearm and foot volume $<1 / 3$ of the proximal leg value in Case II-1. 
Table 3 Ultrastructural features of myopathology of the four cerebrotendinous xanthomatosis patients

\begin{tabular}{|c|c|c|c|c|}
\hline & $\mathrm{I}-1$ & $\mathrm{I}-2$ & II-1 & II-2 \\
\hline \multicolumn{5}{|l|}{ Changes of mitochondria } \\
\hline subsacrolemmal accumulation & $\begin{array}{l}++ \\
+\end{array}$ & +++ & ++ & + \\
\hline change in size and shape & $\begin{array}{l}++ \\
+\end{array}$ & ++ & ++ & + \\
\hline increase in amount & $\begin{array}{l}++ \\
+\end{array}$ & ++ & ++ & + \\
\hline \multicolumn{5}{|l|}{ Changes of membranous system } \\
\hline triads proliferation, swollen & - & ++ & + & - \\
\hline $\begin{array}{l}\text { increased amount of sacroplasmic } \\
\text { reticulum }\end{array}$ & + & $\begin{array}{l}+++ \\
+\end{array}$ & - & +++ \\
\hline laminated bodies & - & - & - & ++ \\
\hline membranous debris & $\begin{array}{l}++ \\
+\end{array}$ & ++ & ++ & ++ \\
\hline Increased amount of lipid droplets & + & ++ & $\begin{array}{l}++ \\
+\end{array}$ & $\begin{array}{l}+++ \\
+\end{array}$ \\
\hline Increased amount of lipofuscin & + & + & + & ++ \\
\hline Increased amount of glycogen & ++ & ++ & + & ++ \\
\hline
\end{tabular}

$+=$ positive; - = negative; the number of " + " = different amounts

Reported CTX patients with peripheral neuropathy: summary of clinical features (Table 5 )

In the literature review, we found 13 reports [5-17] that had studied peripheral neuropathy of CTX patients. The clinical and laboratory data of these studies were included for analysis.

\section{Discussion}

\section{Peripheral Nerve Abnormality}

CTX is an uncommon lipid storage disease, and its associated neuromuscular abnormalities have rarely been examined in large-scale studies. The reported CTX cases with peripheral neuropathy [5-17] used different measurement methods (NCS and/or EMG and/or sural nerve biopsy and/or muscle biopsy) for assessment and confirmation, and also listed differently-described types of peripheral neuropathy (Table 5). Because of these differences in clinical evaluation and study results, a matter of debate in the pathologic findings and etiologies of peripheral neuropathy in CTX were also elicited among these reports [5-17]. Mondelli et al. [13], used electrophysiologic studies including NCS, and they found that eight CTX patients had a moderate sensori-motor neuropathy of demyelinating type, but this finding was not further confirmed by pathological study of nerve. Argov et al. [9] also noted a demyelinating process in a study of peripheral neuropathy in three CTX patients. In another study by Verrips et al. [15] using NCS and EMG studies, seven of their included CTX cases had a peripheral neuropathy (five with axonal type, one with mixed axonal and demyelinating type, and one unspecified), two a normal study and one with myopathic findings. In our study, different degrees of axonal sensory-motor polyneuropathy in three cases and mixed axonal and demyelinating sensori-motor polyneuropathy in one case were found, and their myo-histopathologic features also reflected this neuropathic process showing denervation features. Our study results are consistent with those of Verrips et al. [15] in that axonal degeneration was concluded to be the predominant process of neuropathy in CTX, although in some of their patients, features of chronic demyelination and remyelination were also found [15]. In pathologic studies of peripheral nerves, Voiculescu et al. [10], Donaghy et al. [11] and Wang et al. [17] found the deposition of lipid in Schwann cells in CTX patients with neuropathy, while this pathologic change was not noted in the studies of Katz et al. [8], Argov et al. [9] and Verrips A et al., [15]. Besides our four cases, another 12 CTX patients [15-17] with a peripheral neuropathy had a genetic analysis, but different mutation patterns were noted. This lack of correlation between the genotype and pathogenesis of peripheral neuropathy or other phenotypes was noted in the studies of Verrips et al. [15,34].

\section{Muscle Abnormality}

In the myopathologic study, mild neurogenic change was the main finding of our four CTX cases, and this denervation feature was also found in other related reports of CTX patients with peripheral neuropathy $[7,10,15,18]$. In the ultrastructual study of muscles, the main abnormal findings included changes of the mitochondria and membranous system, and an increased amount of lipid droplets, lipofuscin and glycogen (Table $3)$. These ultrastructual findings are consistent with those reported by Verrips et al. [15] and Federico et al. [18]. Based on these ultrastructural changes, Federico et al. [18] concluded that: the primary alteration of lipid metabolism in CTX might lead to an impairment of the energy processes of muscle and subsequent mitochondrial morphological change. However, all these ultrastructural changes are nonspecific for CTX and can be found in other muscle disorders or can even be a normal constituent of human skeletal muscles [15,24,25]. Compared with the nervous system, muscles are not a preferable site for cholestanol deposition [35], but all these ultrastructural changes can be attributed to an abnormal metabolic state in CTX which is reflected by the abnormality of the membrane system and abnormal deposition of lipid droplets, lipofuscion and glycogen as shown in this study.

\section{ANS Abnormality}

In the literature, the state of ANS in CTX has only been described in two case reports $[14,16]$. In the report of Geraldes et al. [16], no involvement of the ANS in a 
Figure 1

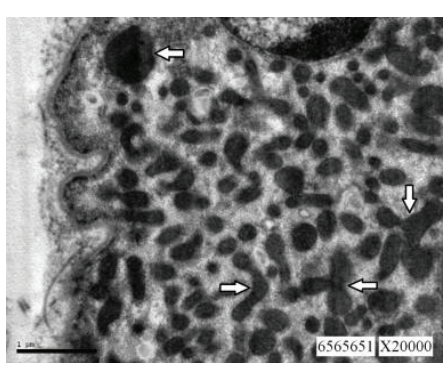

a

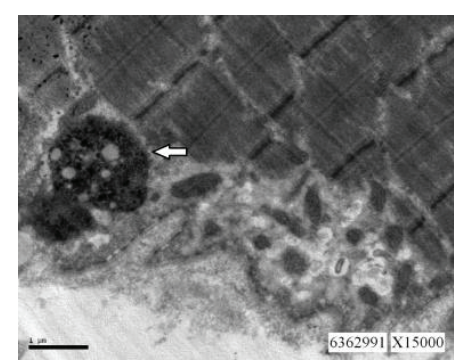

d

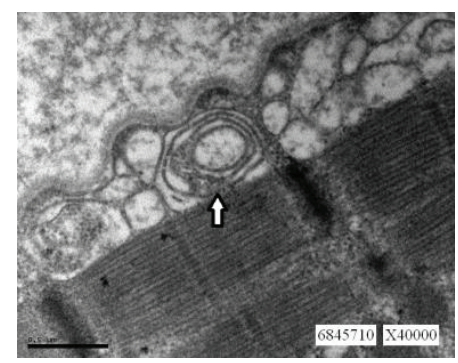

g
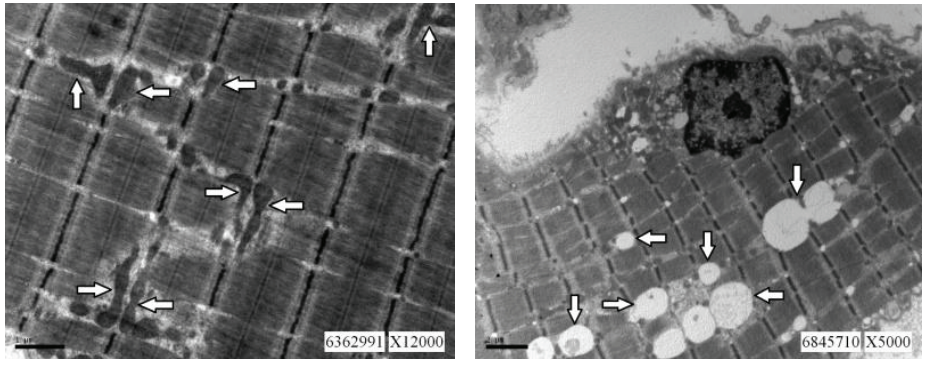

b

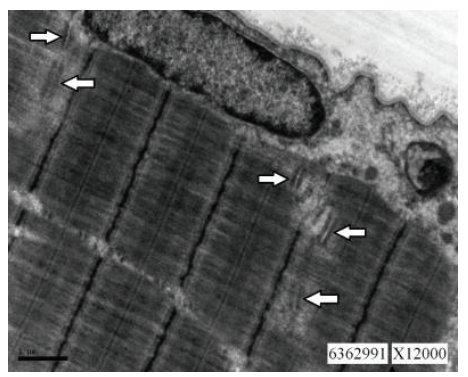

C

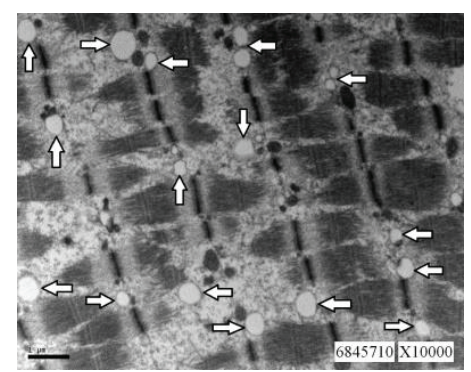

e

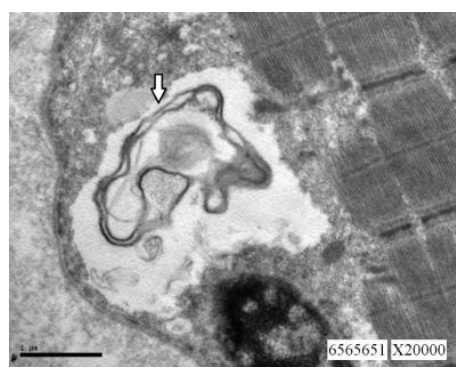

f

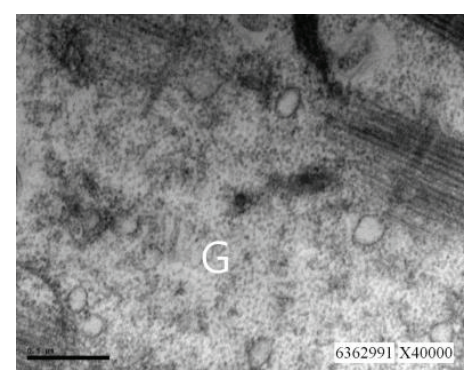

Figure 1 Summarized muscle ultrastructural findings of the four cerebrotendinous xanthomatosis cases. 1a. subsacrolemmal accumulation of mitochondria (arrow), (bar $=1 \mu \mathrm{m})$; 1b. mitochondria change in shape and enlarged in size (arrow), (bar $=1 \mu \mathrm{m}) ; 1 \mathrm{c}$. increased amount of lipid droplets (arrow), (bar = $2 \mu \mathrm{m}) ; 1 \mathrm{~d}$. lipofuscin (arrow), (bar = $1 \mu \mathrm{m})$; 1e. triads proliferation (arrow), (bar = $1 \mu \mathrm{m}) ; 1 \mathrm{f}$. swollen sacroplasmic reticulum (arrow), (bar $=1 \mu \mathrm{m}) ; 1 \mathrm{~g}$. laminated bodies (arrow), (bar $=0.5 \mu \mathrm{m}) ; 1 \mathrm{~h}$. membranous-like debris (arrow) in the subsacrolemmal space, (bar $=1 \mu \mathrm{m})$; 1i. increased amount of glycogen (marked as $\mathrm{G}$, bar $=0.5 \mu \mathrm{m}$ ).

CTX case with severe neuropathy was found. However in the report of Arpa et al. [14], an opposite result was found, showing a postganglionic cholinergic failure in a CTX patient with somatic peripheral neuropathy. In this study, we arranged multiparametric evaluation (SSR, RRIV, HUT study for orthostatic BP and HR recording, and Q-Sweat recording) to assess the functional state of ANS of the four CTX patients. The evaluation results revealed different degrees of laboratory evidence of ANS abnormalities in three of the four CTX patients, in which both sympathetic and parasympathetic systems were involved (Table 4). Despite these different degrees of laboratory abnormalities were demonstrated, they were not reflected fully in clinical blood pressure and heart rate changes in these four cases. In the meanwhile, there was also a mismatch in the inter-lab data such as the finding of SSR and Q-Sweat test. These mismatches need further verification by large-scale study.

This ANS abnormality can be partially reflected pathologically by the findings of skin biopsy IENF measurement, which is a reliable tool with high diagnostic specificity and good sensitivity for small fiber disease [36-38]. In a study conducted by Schuller et al. [39], a comparison of the three small fiber systems revealed that functionally different systems were damaged independently, and isolated affection of each fiber type was frequently observed. Therefore, biopsy results must be interpreted in conjunction with neurologic findings and laboratory results, including 
Table 4 Autonomic findings

\begin{tabular}{|c|c|c|c|c|c|}
\hline & & $\mathrm{I}-1$ & $\mathrm{I}-2$ & II-1 & $\mathrm{II}-2$ \\
\hline RRIV (\%) $(N>15)$ & & 3.53 & 15.7 & 24.2 & 25.4 \\
\hline Head-up tilt test & & NR & NR & NR & NR \\
\hline BR sensitivity (msec/mmHg) & & -1.9 & -1.4 & 2.3 & 0.7 \\
\hline $30: 15$ ratio $(\mathrm{N}>1.03)$ & & 1.03 & 0.95 & 1.11 & 1.37 \\
\hline \multicolumn{6}{|l|}{ SSR } \\
\hline \multirow[t]{4}{*}{ onset latency (ms) } & R palm & 1320 & 1700 & 1440 & 1720 \\
\hline & L palm & 1400 & 1700 & 1400 & 1770 \\
\hline & R sole & 2300 & 2280 & 2060 & 2280 \\
\hline & L sole & 2290 & 2280 & 2250 & 2280 \\
\hline \multirow[t]{4}{*}{ amplitude $(\mu \mathrm{V})$} & R palm & 2652 & 1569 & 978 & 1314 \\
\hline & L palm & 2198 & 921 & 869 & 1099 \\
\hline & R sole & 315 & 159 & 61 & 688 \\
\hline & L sole & 399 & 239 & 74 & 562 \\
\hline \multicolumn{6}{|l|}{ Q-Sweat test } \\
\hline \multirow[t]{4}{*}{ onset latency (seconds) } & Forearm & 137 & 219 & 185 & 275 \\
\hline & Proximal leg & 217 & 194 & 165 & 128 \\
\hline & Distal leg & 165 & 148 & 168 & 136 \\
\hline & Foot & 165 & 203 & 189 & 122 \\
\hline \multirow[t]{4}{*}{ total volume $(\mu \mathrm{l})$} & Forearm & 0.150 & 0.298 & 0.015 & 0.450 \\
\hline & Proximal leg & 0.134 & 0.063 & 0.199 & 1.283 \\
\hline & Distal leg & 0.183 & 0.108 & 0.294 & 1.409 \\
\hline & Foot & 0.029 & 0.095 & 0.030 & 0.700 \\
\hline \multirow[t]{4}{*}{ skin temperature $\left({ }^{\circ} \mathrm{C}\right)$} & Forearm & 36.5 & 36.4 & 36.5 & 35.4 \\
\hline & Proximal leg & 35 & 35.8 & 36.4 & 35.7 \\
\hline & Distal leg & 35.6 & 36.3 & 34.9 & 35.3 \\
\hline & Foot & 35.7 & 35.2 & 34.7 & 35.4 \\
\hline room temperature $\left({ }^{\circ} \mathrm{C}\right)$ & & 23 & 21 & 21 & 21 \\
\hline room humidity (\%) & & 56 & 57 & 58 & 58 \\
\hline
\end{tabular}

RRIV: R-R interval variation; NR: normal blood pressure (BP) and heart rate (HR) response in head-up tilt test: no abnormal change in BP and HR; N: normal; SSR: sympathetic skin response; Q-Sweat: quantitative sweat measurement.

In Q-Sweat test, the total sweat volume (median ( $\mathrm{min}, \mathrm{max}$ ) for female normal control were $0.495(0.02,3.814)$ (forearm), 0.505 (0.06, 4.49$)$ (proximal leg), 0.389 $(0.015,4.914)$ (distal leg) and $0.203(0.014,0.802)$ (foot), and for male normal control were $1.079(0.02,3.814)$ (forearm), 1.091 (0.029, 2.734$)$ (proximal leg), 1.107 $(0.043,2.902)$ (distal leg) and 0.585 (0.041, 1.718) (foot).

Table 5 Clinical and laboratory data of the reported cerebrotendinous xanthomatosis patients with peripheral neuropathy [5-17]

\begin{tabular}{|c|c|c|c|c|c|}
\hline $\begin{array}{l}\text { Reference } \\
\text { No/ year }\end{array}$ & $\begin{array}{l}\text { Total case No/gene mutation/ age or } \\
\text { range of age }(y / r)\end{array}$ & Described type of neuropathy & $\begin{array}{l}\text { Nerve } \\
\text { conduction study }\end{array}$ & $\begin{array}{l}\text { Sural nerve } \\
\text { biopsy }\end{array}$ & $\begin{array}{l}\text { Muscle } \\
\text { biopsy }\end{array}$ \\
\hline$[5] / 1079$ & 4/ND/12-27 & S-M pnp & D & ND & ND \\
\hline$[6] / 1979$ & 1/ND/25 & ND & D & $\mathrm{D}$ & ND \\
\hline$[7] / 1984$ & 4/ND/35-43 & S-M pnp & D & D & $\mathrm{D}$ \\
\hline$[8] / 1985$ & $1 / N D / 50$ & S-M pnp & D & D & ND \\
\hline$[9] / 1986$ & 3/ND/14-30 & demyelinated S-M pnp & D & D & ND \\
\hline [10]/1987 & 1/ND/29 & S-M pnp & $\mathrm{D}$ & $D$ & $D$ \\
\hline [11]/1990 & 1/ND/30 & S-M pnp & D & $D$ & ND \\
\hline$[12] / 1991$ & $1 / \mathrm{ND} / 22$ & Axonal pnp & D & $\mathrm{D}$ & ND \\
\hline$[13] / 1992$ & 10/ND/26-44 & $\begin{array}{l}\text { Mixed S-M pnp (2) and } \\
\text { demyelinating S-M pnp (8) }\end{array}$ & D & ND & ND \\
\hline$[14] / 1995$ & 1/ND/34 & Mixed & D & ND & ND \\
\hline$[15] / 2000$ & $10 / D^{a} / 24-54$ & $\begin{array}{l}\text { Axonal pnp (5), mixed pnp (1), pnp } \\
\text { (1) }\end{array}$ & D & $\mathrm{D}$ & D \\
\hline$[16] / 2007$ & $1 / D^{b} / 47$ & Polyneuropathy & D & ND & ND \\
\hline$[17] / 2007$ & $1 / D^{c} / 42$ & S-M polyneuropathy & D & $\mathrm{D}$ & ND \\
\hline
\end{tabular}

No = number; ND = not determined; $\mathrm{D}=$ determined; $\mathrm{S}-\mathrm{M}$ = sensori-motor; pnp = peripheral neuropathy;

${ }^{\mathrm{a}}=$ mutations on both alleles of the CYP 27 gene in all 10 patients (Table 1 of [15])

${ }^{b}=$ mutations $1016 \mathrm{C}>\mathrm{T}(\mathrm{T} 339 \mathrm{M})$ and $1183 \mathrm{C}>\mathrm{T}(\mathrm{R} 395 \mathrm{C})$ in the CYP21A2 gene

${ }^{c}=$ mutations $379 \mathrm{C}>\mathrm{T}(\mathrm{R} 94 \mathrm{~W})$ and $1420 \mathrm{C}>\mathrm{T}(\mathrm{R} 441 \mathrm{~W})$ in the CYP27A1 gene 
complementary testing of several small somatic systems and ANS. But again, as shown in this study, there is a discrepancy between the finding of IENF density measurement and Q-Sweat test. This mismatch of the inter-lab data also needs further large scale study for verification. In this study, IENF density measurement revealed a relatively high incidence $(75 \%, 3 / 4)$ of small fiber involvement in CTX, and this figure of incidence is as high as those neuropathies with a small-fiber sensory neuropathy [40-43].

\section{Conclusion}

Peripheral neuropathy, especially the subtype axonal sensori-motor neuropathy, is common in patients with CTX. Evidence of lipid metabolic derangement in CTX can be reflected in ultrastructural studies of muscles. With an adequate multi-parametric evaluation, a high incidence of ANS abnormality can be seen in this uncommon lipid-storage disease, and a high incidence of small fiber involvement is also reflected in the IENF density measurement of skin biopsies. This study is limited by its small case number, but it may shed light on further studies of the clinical and laboratory involvements in CTX.

\section{Acknowledgements}

The authors thank Prof Hsieh ST (Department of Neurology and Department of Anatomy and Cell Biology, National Taiwan University College of Medicine, Taipei, Taiwan) for his help in skin innervation quantification. The authors also want to express their gratitude to the patients and their families for participating in this study.

\section{Author details}

'Department of Neurology, Kaohsiung Chang Gung Memorial Hospital and Chang Gung University College of Medicine, Kaohsiung, Taiwan. ${ }^{2}$ Department of Biological Science, National Sun Yat-Sen University, Kaohsiung, Taiwan.

\section{Authors' contributions}

All authors have read and approved the final manuscript. SFC had substantial contributions to conception and design, data acquisition and analysis, drafting the manuscript and revising the manuscript. NWT, CCC, $\mathrm{CHL}, \mathrm{CRH}$ and YCC had substantial contributions to conception and design, clinical data analysis. WNC had substantial contributions to conception and design, data analysis, critical revision and final approval of the revision.

\section{Competing interests}

The authors declare that they have no competing interests.

Received: 4 December 2010 Accepted: 31 May 2011

Published: 31 May 2011

\section{References}

1. Berginer VM, Salen G, Shefer S: Cerebrotendinous xanthomatosis. In Neurogenetic Disorders. Edited by: Johnson WG. Philadelphia: Saunders; 1989:55-74.

2. Verrips A, Hoefsloot LH, Steenbergen GCH, Theelen JP, Wevers RA, Gabreëls FJM, van Engelen BGM, van den Heuvel PWJ: Clinical and molecular genetic characteristics of patients with cerebrotendinous xanthomatosis. Brain 2000, 123:908-919.

3. Federico A, Dotti MT: Cerebrotendinous xanthomatosis: clinical manifestations, diagnositic citeria, pathogenesis, and therapy. J Child Neurol 2003, 18:633-638.
4. Moghadasian $\mathrm{MH}$ : Cerebrotendinous xanthomatosis: clinical course, genotypes and metabolic backgrounds. Clin Invest Med 2004, 27:42-50.

5. Kuritzky A, Berginer VM, Korczyn AD: Peripheral neuropathy in cerebrotendinous xanthomatosis. Neurology 1979, 29:880-881.

6. Ohnishi A, Yamashita Y, Goto I, Kuroiwa Y, Murakami S, Ikeda M: De- and re-myelination and onion bulb in cerebrotendinous xanthomatosis. Acta Neuropathol (Berlin) 1979, 45:43-45.

7. Pop PH, Joosten E, van Spreeken A, Gabreëls-Festen A, Jaspar H, ter Laak H, Vos A: Neuroaxonal pathology of central and peripheral nervous systems in cerebrotendinous xanthomatosis. Acta Neuropathol 1984, 64:259-264.

8. Katz DA, Scheinberg L, Horoupian DS, Salen G: Peripheral neuropathy in cerebrotendinous xanthomatosis. Arch Neurol 1985, 42:1008-1010.

9. Argov Z, Soffer D, Eisenberg S, Zimmerman Y: Chronic demyelinating peripheral neuropathy in cerebrotendinous xanthomatosis. Ann Neurol 1986, 20:89-91.

10. Voiculescu V, Alexianu M, Popescu-Tismana G, Pastia M, Petrovici A, Dan A: Polyneuropathy with lipid deposits in Schwann cells and axonal degeneration in cerebrotendinous xanthomatosis. J Neurol Sci 1987, 82:89-99.

11. Donaghy M, King RH, McKeran RO, Schwartz MS, Thomas PK: Cerebrotendinous xanthomatosis: clinical, electrophysiological and nerve biopsy findings, and response to treatment with chenodeoxycholic acid. J Neurol 1990, 237:216-219.

12. Ben Hamida M, Chabbi N, Ben Hamida C, Mhiri C, Kallel R: Peripheral neuropathy in a sporadic case of cerebrotendinous xanthomatosis. Rev Neurol (Paris) 1991, 147:469-475.

13. Mondelli M, Rossi A, Scarpini C, Dotti MT, Federico A: Evoked potentials in cerebrotendinous xanthomatosis and effect induced by chenodeoxycholic acid. Arch Neurol 1992, 49:469-475.

14. Arpa J, Sánchez C, Vega A, Cruz-Martínez A, Ferrer T, López-Pajares R, Muñoz J, Barreiro P: Cerebrotendinous xanthomatosis diagnosed after traumatic subdural haematoma. Rev Neurol 1995, 23:675-678.

15. Verrips A, van Engelen BG, ter Laak H, Gabreels-Festen A, Janssen A, Zwarts M, Wevers RA, Gabreels FJ: Cerebrotendinous xanthomatosis. Controversies about nerve and muscle: observations in ten patients. Neuromuscul Disord 2000, 10:407-414.

16. Geraldes R, Santos-Bento M, de Carvalho M: Cerebrotendinous xanthomatosis: no involvement of the autonomic nervous system in a case with severe neuropathy. Neurophysiol Clin 2007, 37:47-49.

17. Wang Z, Yuan Y, Zhang W, Zhang Y, Feng L: Cerebrotendinous xanthomatosis with a compound heterozygote mutation and severe polyneuropathy. Neuropathology 2007, 27:62-66.

18. Federico A, Dotti MT, Volpi N: Muscle mitochondrial changes in cerebrotendinous xanthomatosis. Ann Neurol 1991, 30:734-735.

19. Wang PW, Chang WN, Lu CH, Chao D, Schrag C, Pan TL: New insights into the pathological mechanisms of cerebrotendinous xanthomatosis in the Taiwanese using genomic and proteomic tools. Proteomics 2006, 6:1029-1037.

20. Su CS, Chang WN, Huang SH, Lui CC, Pan TL, Lu CH, Chuang YC, Huang CR, Tsai NW, Hsieh MJ, Chang CC: Cerebrotendinous xanthomatosis patients with and without parkinsonism: clinical characteristics and neuroimaging findings. Mov Disord 2010, 25:452-458.

21. Chang CC, Lui CC, Wang JJ, Huang SH, Lu CH, Chen C, Chen CF, Tu MC, Huang CW, Chang WN: Multi-parametric neuroimaging evaluation of cerebrotendinous xanthomatosis and its correlation with neuropsychological presentations. BMC Neurol 2010, 10:59.

22. Lin KP, Chan MH, Wu ZA: Nerve conduction studies in healthy Chinese: correlation with age, sex, height and skin temperature. Chin Med J (Taipei) 1993, 52:293-297.

23. Sewry CA, Molnar MJ: Histopathology and immunoanalysis of muscle. In Disorders of Voluntary Muscles. Edited by: Karpati G, Hilton-Jones D, Bushby K, Griggs RC. Cambridge: Cambridge University Press; 2010:93-127.

24. Oldfors A: Ultrastructural study of muscle. In Disorders of Voluntary Muscle. Edited by: Karpati G, Hilton-Jones D, Bushby K, Griggs RC. Cambridge: Cambridge University Press; 2010:128-150.

25. Dubowitz V, Sewry CA: Ultrastructural changes in diseased muscle. In Muscle Biopsy: a practical approach. Edited by: Dubowitz V, Sewry CA. Philadelphia: Saunders; 2007:125-194.

26. Yang NC, Lee MJ, Chao CC, Chuang YT, Lin WM, Chang MF, Hsieh PC, Kan HW, Lin YH, Yang CC, Chiu MJ, Liou HH, Hsieh ST: Clinical 
presentations and skin denervation in amyloid neuropathy due to transthyretin Ala97Ser. Neurology 2010, 75:532-538.

27. Tseng MT, Hsieh SC, Shun CT, Lee KL, Pan CL, Lin WM, Lin YH, Yu CL, Hsieh ST: Skin denervation and cutaneous vasculitis in systemic lupus erythematosus. Brain 2006, 129:977-985.

28. Shun CT, Chang YC, Wu HP, Hsieh SC, Lin WM, Lin YH, Tai TY, Hsieh ST: Skin denervation in type 2 diabetes: correlations with diabetic duration and functional impairments. Brain 2004, 127:1593-1605.

29. Ewing DJ: Cardiovascular reflexes and autonomic neuropathy. Clin Sci Mol Med 1978, 55:321-327.

30. Ewing DJ, Campbell IW, Murray A, Neilson JMM, Clarke BF: Immediate heart-rate response to standing: simple test for autonomic neuropathy in diabetes. Br Med J 1978, 21:145-147.

31. Parati G, Di Rienzo M, Mancia G: How to measure baroreflex sensitivity: from the cardiovascular laboratory to daily life. J Hypertens 2000, 18:7-19.

32. Gratze G, Fortin J, Holler A, Grasenick K, Pfurtscheller G, Wach P, Schonegger J, Kotanko P, Skrabal F: A software package for non-invasive, real-time beat-to-beat monitoring of stroke volume, blood pressure, total peripheral resistance and for assessment of autonomic function. Comput Biol Med 1998, 28:121-142.

33. Sletten DM, Weigand SD, Low PA: Relationship of Q-sweat to quantitative sudomotor axon reflex test (QSART) volumes. Muscle Nerve 2010, 41:240-246.

34. Verrips A, Hoefsloot LH, Steenbergen GC, Theelen JP, Wevers RA, Gabreels FJ, van Engelen BG, van den Heuvel LP: Clinical and molecular genetic characteristics of patients with cerebrotendinous xanthomatosis. Brain 2000, 123:908-919.

35. Bhattacharyya AK, Lin DS, Connor WE: Cholestanol metabolism in patients with cerebrotendinous xanthomatosis: absorption, turnover, and tissue deposition. J Lipid Res 2007, 48:185-192.

36. Devigili G, Tugnoli V, Penza P, Camozzi F, Lombardi R, Melli G, Broglio L, Granieri E, Lauria G: The diagnostic criteria for small fiber neuropathy: from symptoms to neuropathology. Brain 2008, 131:1912-1925.

37. England JD, Gronseth GS, Franklin G, Carter GT, Kinsella LJ, Cohen JA, Asbury AK, Szigeti K, Lupski JR, Latov N, Lewis RA, Low PA, Fisher MA, Herrmann D, Howard JF, Lauria G, Miller RG, Polydefkis M, Sumner AJ, American Academy of Neurology; American Association of Neuromuscular and Electrodiagnostic Medicine; American Academy of Physical Medicine and Rehabilitation: Evaluation of distal symmetric polyneuropathy: the role of autonomic testing, nerve bopsy, and skin biopsy (an evidencebased review). Muscle Nerve 2009, 39:106-115.

38. Joint Task Force of the EFNS and the PNS: European Federation of Neurological Societies/Peripheral Nerve Society Guideline on the use of skin biopsy in the diagnosis of small fiber neuropathy. Report of a joint task force of the European Federation of Neurological Societies and the Peripheral Nerve Society. J Peripher Nerv Syst 2010, 15:79-92.

39. Schuller TB, Hermann K, Baron R: Quantitative assessment and correlation of sympathetic, parasympathetic, and afferent small fiber function in peripheral neuropathy. $J$ Neurol 2000, 247:267-272.

40. Pan CL, Tseng TJ, Lin YH, Chiang MC, Lin MW, Hsieh ST: Cutaneous innervations in Guillain-Barre syndrome: pathology and clinical correlation. Brain 2003, 126:386-397.

41. Shun CT, Chang YC, Wu HP, Hsieh SC, Lin WM, Lin YH, Tai TY, Hsieh ST: Skin denervation in type 2 diabetes: correlation with diabetic duration and functional impairment. Brain 2004, 127:1593-1605.

42. Tseng MT, Hsieh SC, Shun CT, Lee KL, Pan CL, Lin WM, Lin YH, Yu CL, Hsieh ST: Skin denervation and cutaneous vasculitis in systemic lupus erythomatosus. Brain 2006, 129:977-985.

43. Chao CC, Hsieh ST, Shun CT, Hsieh SC: Skin denervation and cutaneous vasculitis in eosinophilia-associated neuropathy. Arch Neurol 2007, 64:401-404.

\section{Pre-publication history}

The pre-publication history for this paper can be accessed here: http://www.biomedcentral.com/1471-2377/11/63/prepub

doi:10.1186/1471-2377-11-63

Cite this article as: Chen et al: Neuromuscular abnormality and autonomic dysfunction in patients with cerebrotendinous xanthomatosis. BMC Neurology 2011 11:63.

\section{Submit your next manuscript to BioMed Central and take full advantage of:}

- Convenient online submission

- Thorough peer review

- No space constraints or color figure charges

- Immediate publication on acceptance

- Inclusion in PubMed, CAS, Scopus and Google Scholar

- Research which is freely available for redistribution

Submit your manuscript at www.biomedcentral.com/submit
C Biomed Central 